\title{
Preparation and Properties of Flame Retardant ABS/POK Alloy
}

\author{
Wangping Qin, Jingfeng Fu, Xiaoyun Yang, Nanbiao Ye \\ National Engineering Laboratory for Plastic Modification and Processing, Kingfa Science and Technology Co., Ltd., Guangzhou, China
}

\section{Email address:}

qinwangping@kingfa.com (Wangping Qin)

\section{To cite this article:}

Wangping Qin, Jingfeng Fu, Xiaoyun Yang, Nanbiao Ye. Preparation and Properties of Flame Retardant ABS/POK Alloy. American Journal of Mechanical and Materials Engineering. Vol. 4, No. 1, 2020, pp. 12-17. doi: 10.11648/j.ajmme.20200401.12

Received: March 9, 2020; Accepted: March 23, 2020; Published: April 14, 2020

\begin{abstract}
Background ABS material has excellent mechanical properties, but its solvent resistance is poor. Acid solvents are prone to cracking, which will affect the normal use of the product. Technical research is needed to improve this performance defect and solve the technical bottleneck of poor solvent resistance of ABS material, so as to meet the technical demand of energy and other fields and improve the market application field of ABS material. Subject Using ABS and POK resin alloy as matrix resin, a high performance flame retardant ABS alloy material was prepared by developing a high efficiency flame retardant system of brominated antimony. Methods The mechanical properties, crystallization behavior, wear resistance, solvent resistance and heat resistance of the alloy materials were characterized by Fourier infrared spectroscopy, differential scanning calorimeter, universal testing machine, scanning electron microscope and friction tester. Result ABS has a good compatibility with POK, and the alloy material containing 20\% POK has excellent mechanical properties and heat resistance, good ice acetic acid resistance and excellent solvent resistance. Through the DSC curve of the alloy material, the relationship between the melting peak area and the content of POK resin was obtained. POK resin can significantly improve the wear resistance of ABS and has a good glossiness retention rate.
\end{abstract}

Keywords: POK, Flame Retardant Alloy, Solvent Resistance, Wear Resistance

\section{Introduction}

ABS resin has excellent comprehensive properties [1-4] and is widely used in household appliances, electronics and electrical industries $[5,6]$. However, its solvent resistance is general and it is prone to cracking in acidic environments. Such performance defects seriously affect product functions and normal use, and also limit its promotion and application in special chemical environments [7, 8]. Polyketone resin (POK) is a kind of carbon monoxide, ethylene, propylene, ternary copolymer synthesis of a new type of green polymer, this special chemical structure gives its excellent properties, solvent resistance has reached the level of PPS, wearability is more than 10 times of POM, low noise effect is outstanding, and green environmental protection, do not contain harmful substances, is a kind of engineering plastics that could satisfy the requirement of food grade. At present, the research on polyketone materials is still blank in the field of polymer materials. Most scholars do not realize the scientific value of the study of polyketone, which has great development potential in the aspects of functionalization and flame retardation. This material has made outstanding contributions to environmental protection, energy conservation and emission reduction in human society. The study of polyketone materials is a basic frontier scientific subject, and it will have a great influence on the industry in the future with its special performance advantages. In the future, polyketone alloy materials will become a hot research direction in the field of polymer materials, and will be the best choice to replace.

\section{Experiment Part}

\subsection{Materials}

The materials used for this research include:

i. POK resin: $\mathrm{M} 330 \mathrm{~A}$

ii. ABS resin: PA-757

iii. Toughening agent: 60POWDER

iv. Compatibilizer: SAG-002 
v. Bromine flame retardant: FR-245

vi. Antimony flame retardant: S-12N

vii. vii. Other additives: market

\subsection{Instruments and Equipment}

High-speed mixer, shr-100a, jiangsu zhangjiagang keda machinery co., LTD; Twin screw extruder, shj-30, nanjing ruia high polymer equipment co., LTD.; Injection molding machine, b-920, zhejiang haitan injection molding machine co., LTD.; Melt flow rate meter, ZR21452, mester industrial systems (China) co., LTD.; Microcomputer controlled electron-ic universal testing machine, 6103. shenzhen sansi company; Electronic universal testing machine, UTM14292, shenzhen sansi company; Impact testing machine, hit5.5p, Zwick /Roell, USA; UL 94 vertical combustion apparatus, hvul-2, ATLAS; Differential scanning calorimeter (DSC): DSC 200 F3, NETZSCH, Germany; Scanning electron microscope (SEM), S250, Cambridge scanning electron microscope company, UK.

\subsection{Sample Preparation}

ABS resin, POK resin, flame retardants, etc. are added into the high-speed mixer at the specified proportion for premix, and then put into the twin screw extruder for extrusion granulation. he barrel of the extruder is divided into 10 sections to control the temperature, the extrusion temperature is between $160{ }^{\circ} \mathrm{C}$ and $200^{\circ} \mathrm{C}$, the main engine speed is 900 $\mathrm{r} / \mathrm{min}$, and the feeding speed is $360 \mathrm{r} / \mathrm{min}$. Extruded and granulated to obtain flame-retardant alloy material, the particle was dried at $80^{\circ} \mathrm{C}$ for $2 \sim 3 \mathrm{~h}$, and injected into standard test spline by injection molding machine (injection temperature $190 \sim 200^{\circ} \mathrm{C}$ ).

Processing AIDS are some functional compounds that must be added to improve the properties of polymers during molding. The processing AIDS used in this paper mainly include 1010 main oxygen agent $0.1 \%, 168$ antioxidant $0.2 \%$, anti-dropping agent $0.2 \%$ and zinc stearate $0.3 \%$, a total of $0.8 \%$. The composition and proportion of materials in this paper are shown in table 1.

Table 1. Composition and proportion of alloy materials.

\begin{tabular}{llllll}
\hline Components & 1\# & 2\# & 3\# & 4\# & 5\# \\
\hline ABS PA-757 & 77.2 & 64.2 & 54.2 & 44.2 & 34.2 \\
POK M330A & & 10 & 20 & 30 & 40 \\
60POWDER & 3 & 3 & 3 & 3 & 3 \\
SAG-002 & & 3 & 3 & 3 & 3 \\
FR-245 & 16 & 16 & 16 & 16 & 16 \\
S-12N & 3 & 3 & 3 & 3 & 3 \\
processing agent & 0.8 & 0.8 & 0.8 & 0.8 & 0.8 \\
\hline
\end{tabular}

Flame retardant ABS polyketone alloy materials were designed and developed with PA-757 and POK 330A as resin matrix, styrene-acrylonitrile-methacrylate copolymer SAG-002 as compatibilizer, FR-245 and S-12N as flame retardant system, and high rubber powder 60POWDER as toughening agent.

\subsection{Performance Test Condition}

The tensile strength was tested in accordance with ISO $527-2: 2012$ and the tensile speed was $50 \mathrm{~mm} / \mathrm{min}$. Elongation at break was tested in accordance with ISO 527-2:2012, with a tensile speed of $50 \mathrm{~mm} / \mathrm{min}$. Bending strength was tested in accordance with ISO 178-2:2012 and bending speed was $2 \mathrm{~mm} / \mathrm{min}$. Bending modulus was tested in accordance with ISO 178-2:2012 and the bending speed was $2 \mathrm{~mm} / \mathrm{min}$. Izod notch impact strength was tested in accordance with ISO 180:2000. Tensile strength of weld marks was tested in accordance with ISO 527-2:2012, and the tensile speed was $50 \mathrm{~mm} / \mathrm{min}$. Melt flow rate was tested in accordance with ISO 1133 , with a temperature of $220^{\circ} \mathrm{C}$ and a load of $10 \mathrm{~kg}$. DSC test temperature ranges from $30^{\circ} \mathrm{C}$ to $270^{\circ} \mathrm{C}$, heating rate is $10^{\circ} \mathrm{C} / \mathrm{min}$, the atmosphere is nitrogen. SEM test: spray gold on the surface of the powder sample with a voltage of $10 \mathrm{KV}$. Wear resistance was tested at $500 \mathrm{~g}$ load, frequency 73 times/min, 1000 times friction, test sample glossiness.

\section{Results and Discussions}

The chemical functional group structure of the alloy was analyzed by FT-IR, crystallization behavior was analyzed by DSC, compatibility and phase distribution were analyzed by SEM, and mechanical properties, heat resistance, solvent resistance, wear resistance and other aspects were analyzed by various characterization methods.

\subsection{FT-IR Test Results}

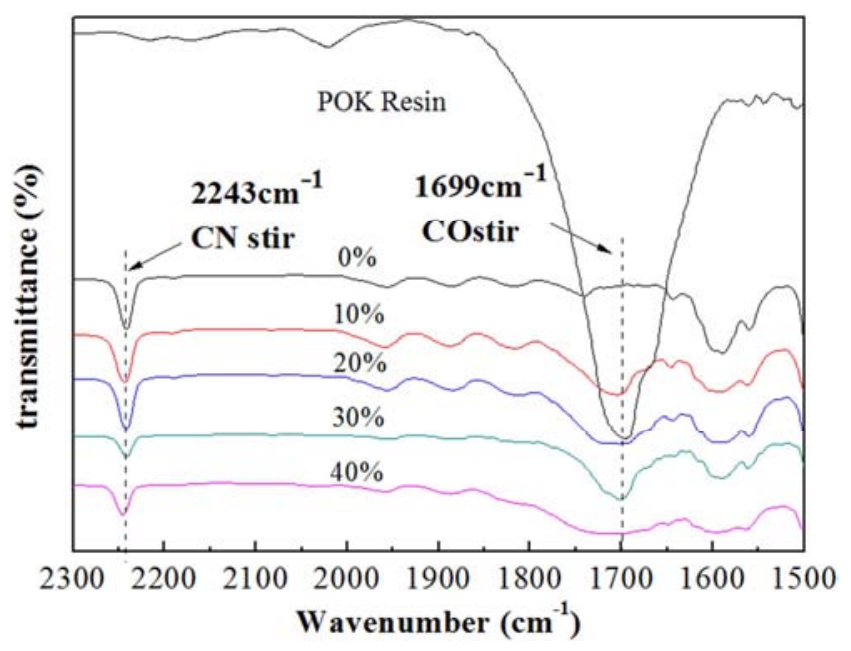

Figure 1. FT-IR spectral of flame retardant ABS polyketo alloy.

FT-IR can characterize the structure of characteristic chemical functional groups of alloy materials. Figure 1 is the infrared spectrum of the alloy material. We can clearly see from the picture, POK resin had obvious in the $1699 \mathrm{~cm}^{-1} \mathrm{C}$ $=\mathrm{O}$ stretching vibration signal, $\mathrm{ABS}$ resin had obvious in the $2243 \mathrm{~cm}^{-1} \mathrm{C} \equiv \mathrm{N}$ stretching vibration signal [9], with the increase of $\mathrm{POK}$ content in the alloy material, $\mathrm{C}=\mathrm{O}$ stretching vibration signal is more and more strong, $\mathrm{C} \equiv \mathrm{N}$ stretching vibration signal is weak, from the strength of the two kinds of functional group of absorbance change obviously reflect the 
alloy material of ABS and the change of the proportion of POK.

\subsection{Thermodynamic Property}

POK resin is a typical crystalline material, its crystallization behavior gives it a very high heat resistance, under the load of $0.45 \mathrm{mpa}$ thermal deformation temperature can reach about $200^{\circ} \mathrm{C}$. Figure 2 shows the DSC heating curve of POK resin and alloy materials with different POK contents. It can be seen that the DSC curve of POK resin has an obvious melting peak. In alloy materials, the area of the melting peak increases with the increase of POK content. As shown in figure 3, the linear equation obtained by linear fitting of the melting peak area of the alloy material in the DSC heating curve and the content of POK resin was obtained [10], and the correlation coefficient $\mathrm{R}^{2}$ was 0.9888 , showing a good linear correlation. For the known melting peak area of the alloy material DSC, the mathematical equation was established to calculate the content of POK resin.

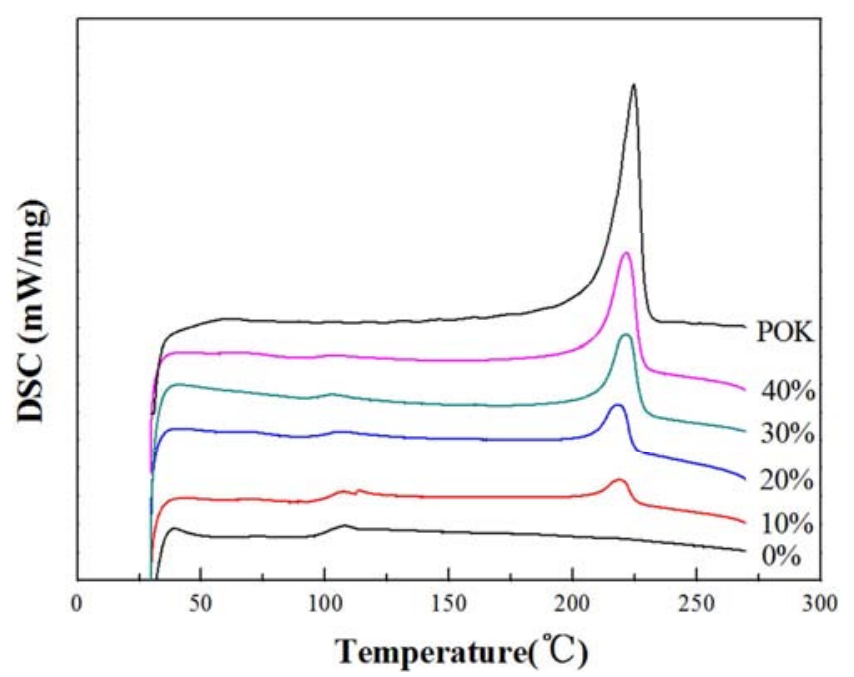

Figure 2. DSC curves of alloy materials with different POK resin contents.

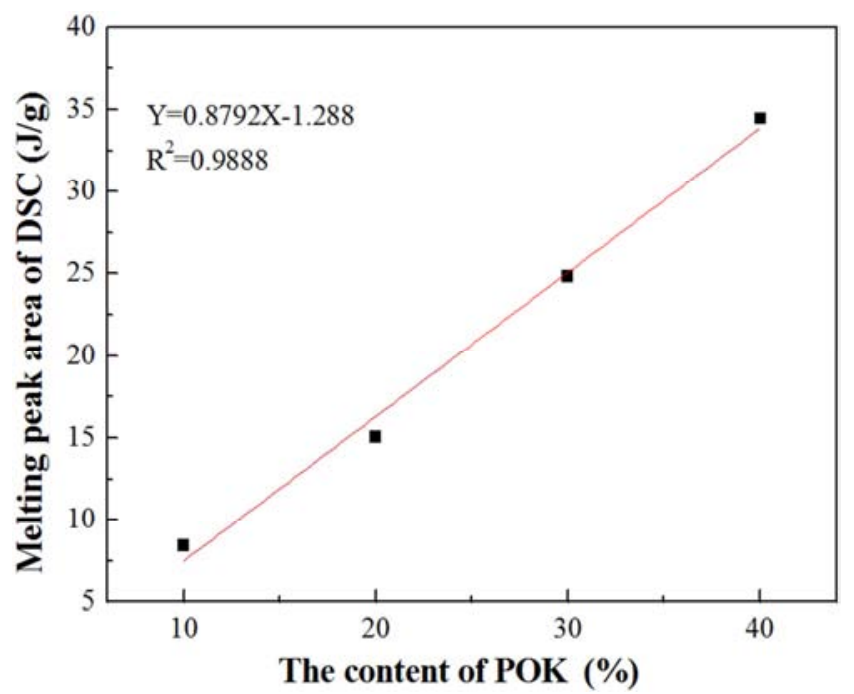

Figure 3. The relationship between the content of $P O K$ resin and the melting peak area of DSC curve.

\subsection{Mechanical Property}

Compared with engineering materials such as nylon, PBT and POM, POK has better impact strength and has the research advantage of ABS material alloying [11-14]. As can be seen from figure 4 and figure 5 , with the increase of POK content, the tensile strength, bending strength and notch impact strength of the alloy materials are all decreasing. On the contrary, the melt flow rate and elongation at break of the material are increasing, and the alloy material has good processing properties and the ability to resist external forces and crack through deformation. The decrease of rigidity and toughness may be caused by some defects at the phase interface between $\mathrm{ABS}$ and $\mathrm{POK}$, and the better melt flow rate is due to the excellent fluidity of POK resin.

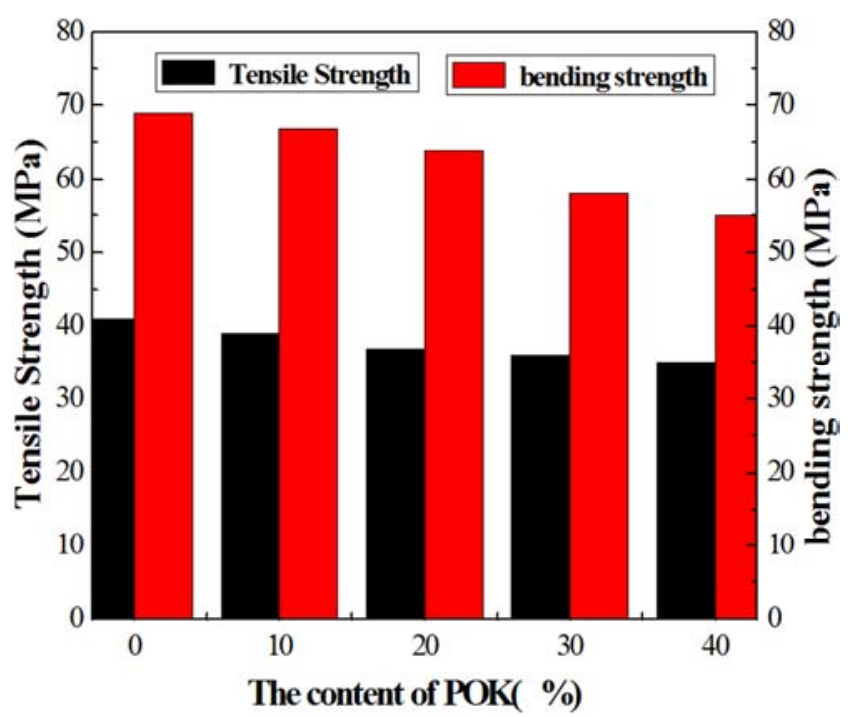

Figure 4. Tensile Strength and bending strength properties of alloy materials with different $P O K$ resin contents.

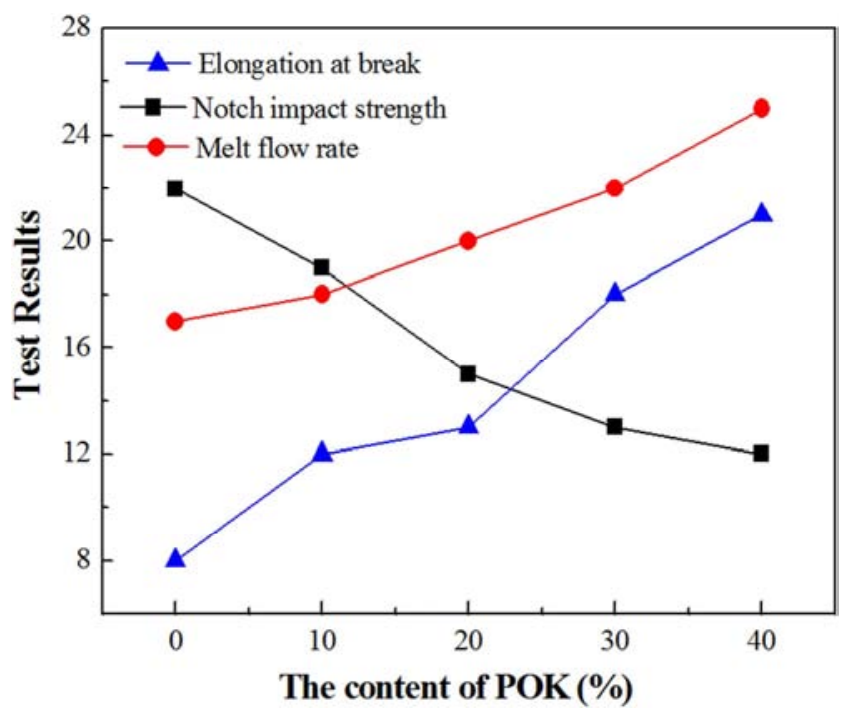

Figure 5. Mechanical properties of alloy materials with different POK resin contents.

In the alloy material system, the compatibility between different phase components has a great influence on the 
mechanical properties, especially the notch impact and the tensile strength of weld marks, which is of great significance to the mechanical properties of the parts [15]. As can be seen from figure 6, with the increase of POK content, the tensile strength of weld marks of the alloy material did not decrease significantly, which was close to the performance of flame retardant ABS. Within the range of $40 \%$ addition, the alloy material had good tensile strength of weld marks, thus ensuring that the product had good mechanical properties.

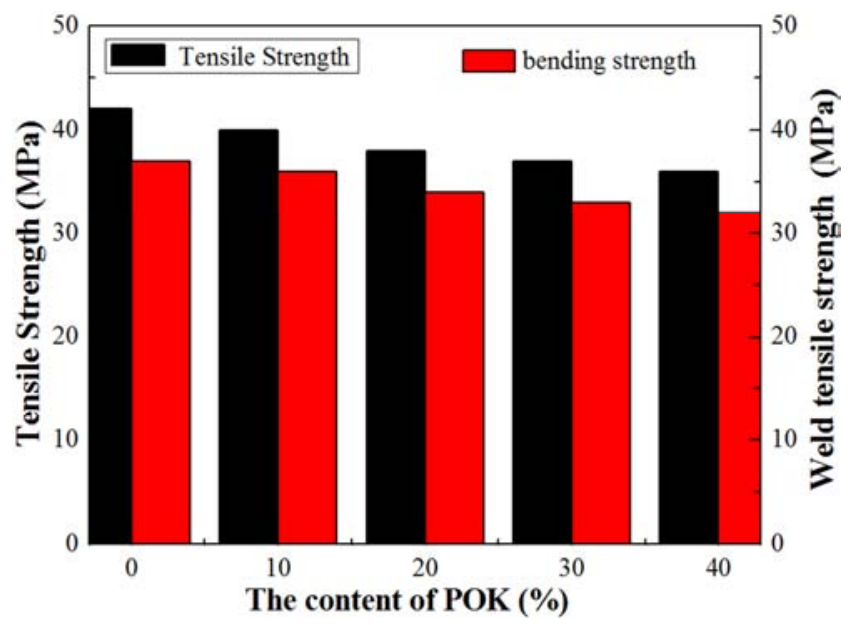

Figure 6. The tensile strength of weld marks of alloy materials with different POK resin contents.

\subsection{Solvent Resistance}

Table 2. Photo of glacial acetic acid resistance of alloy materials with different content of POK resin.

\begin{tabular}{llll}
\hline Initial photos & 5min & 30min \\
\hline & & & \\
\hline
\end{tabular}

Table 3. The results of acetic acid resistance of different POK resin content alloy materials.

\begin{tabular}{|c|c|c|c|c|c|}
\hline Sample number & 1\# & 2\# & $3 \#$ & 4\# & $5 \#$ \\
\hline Content of POK & 0 & 10 & 20 & 30 & 40 \\
\hline $\begin{array}{l}\text { Crack formation } \\
\text { time }\end{array}$ & $12 \mathrm{~s}$ & $23 \mathrm{~s}$ & \multirow{2}{*}{\multicolumn{3}{|c|}{$\begin{array}{l}\text { The spline surface remained } \\
\text { unchanged within } 5 \text { minutes. } \\
\text { There was no crack in the spline } \\
\text { within } 30 \text { minutes }\end{array}$}} \\
\hline Cracking time & $60 \mathrm{~s}$ & $80 \mathrm{~s}$ & & & \\
\hline
\end{tabular}

POK resin exhibits excellent chemical resistance due to its strong c-c bond chemical backbone structure and crystallinity. The solvent resistance of the alloy was evaluated using ISO standard tensile splines at $2.5 \%$ strain. Table 2 and table 3 are the photos and test results of ice acetic acid resistance experiment of alloy materials. In the absence of POK resin, the material has very poor resistance to glacial acetic acid, cracking within 12 seconds and cracking completely within 60 seconds, as in sample 1 . When $10 \%$ POK resin was added, the ice acetic acid resistance of the alloy material was significantly improved and the cracking time was significantly prolonged, as in sample 2 . When the adding amount of $20 \%$ of POK resin, alloy material after 30 minutes without cracks, material is not craze, has very excellent solvent resistance, POK resin content is higher, the better solvent resistance alloy material, but material gloss will be affected, so excellent solvent resistance and other ABS alloy material is unable to achieve [16-18].

\subsection{Heat Resistant Performance}

Figure 7 shows the heat resistance of alloy materials with different POK resin content, which is characterized by thermal deformation temperature and vica softening point temperature $[19,20]$. With the increase of POK resin content, heat distortion temperature of the alloy material and vicat softening point temperature increases, the vicat temperature increase was most pronounced, but on the whole material heat resistance increase is not very high, it may be mainly due to the crystalline POK resin has good compatibility with amorphous of ABS, ABS phase destroyed the POK the crystallization behavior of resin, results in the decrease of POK resin heat resistance contribution to materials, heat resistance increase rate is not very high.

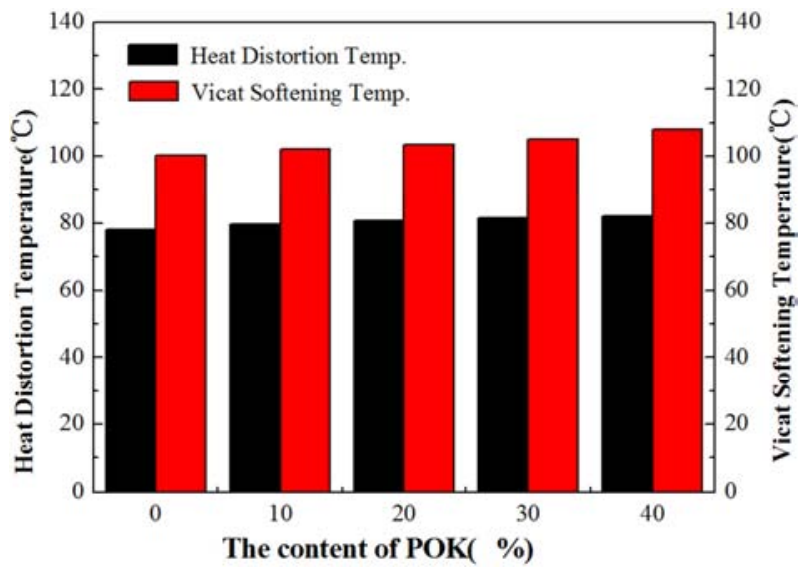

Figure 7. Heat resistance of alloy materials with different POK resin contents.

\subsection{Wear-resisting Performance}

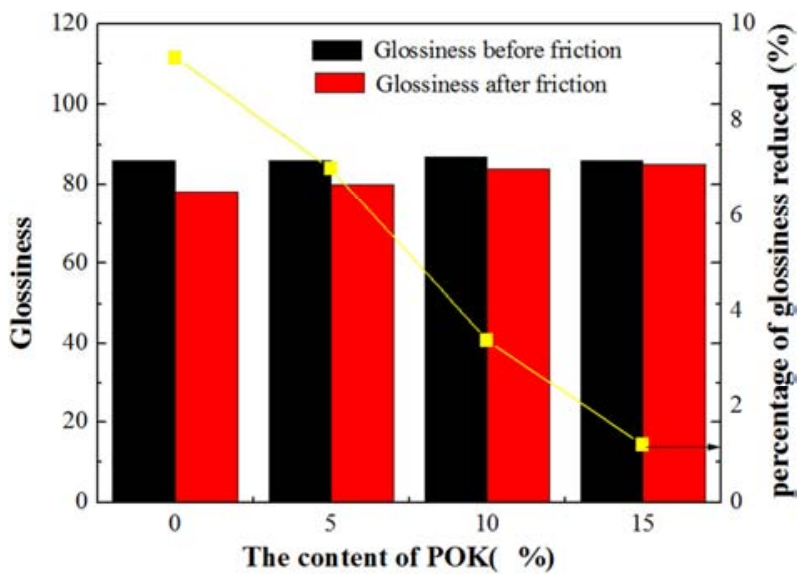

Figure 8. Wear resistance of alloy materials with different POK resin contents. 
Under a certain load, the wear resistance is judged by comparing the glossiness attenuation of materials before and after friction [21]. Figure 8 shows the result of wear resistance of the material. In the alloy material system, with the increase of the content of POK resin, the attenuation degree of the glossiness decreases continuously. When the content of POK reaches $15 \%$, the attenuation degree of the glossiness of the alloy material decreases to less than $2 \%$, showing excellent wear resistance [22].

\subsection{SEM Characterization}

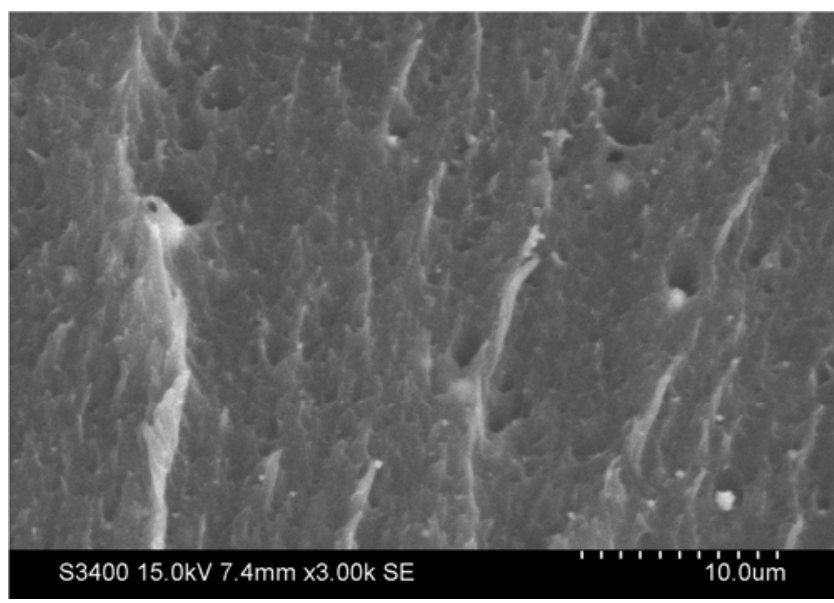

Figure 9. SEM results of flame retardant $A B S$.

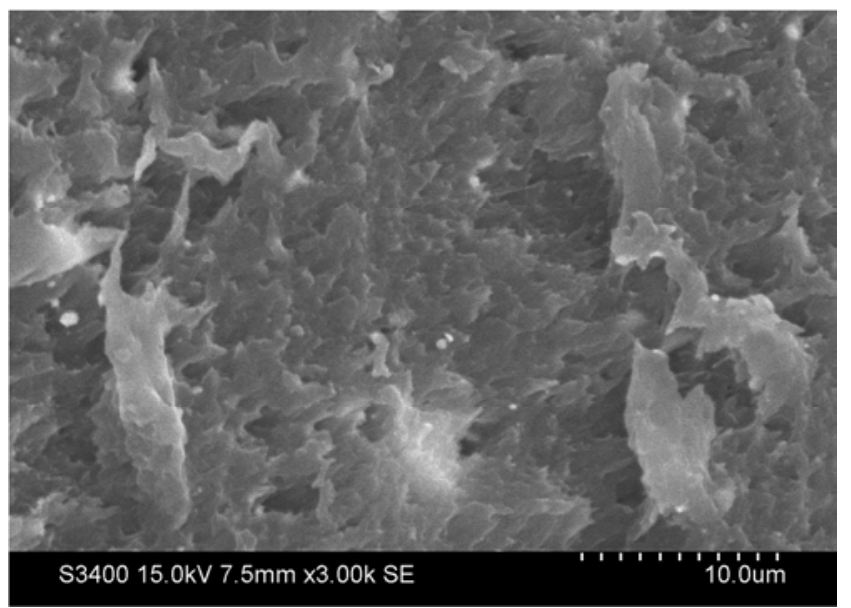

Figure 10. SEM results of flame retardant $A B S / P O K$ alloy materials.

Figure 9 and Figure 10 are the SEM results of flame retardant $\mathrm{ABS}$ and flame retardant $\mathrm{ABS} / \mathrm{POK}$ alloy materials, The POK content of the alloy materials is $20 \%$. It can be seen from the results that the existence of flame retardants will lead to the existence of a certain void at the two-phase interface of the material, and the void at the phase interface of the alloy system material is relatively large. The existence of interfacial void will make the composite easy to produce stress point concentration during stretching, and the stress concentration will make the local stress too large and lead to the fracture of the material, finally resulting in the reduction of the mechanical strength of the material, which is in line with the results of the previous mechanical property test.

\section{Conclusions}

Styrene-acrylonitrile-glycidyl methacrylate amorphous copolymer compatibilizer effectively solves the compatibility between $\mathrm{ABS}$ and $\mathrm{POK}$ resin, and makes the flame retardant ABS/POK alloy material have excellent comprehensive mechanical properties, which meet the needs of industrial application. Through alloying with POK resin, ABS has been greatly improved in heat resistance, wear resistance and solvent resistance, especially in solvent resistance, which meets the solvent resistance requirements of energy products in special chemical environments. Flame retardant ABS/POK has enriched the types of flame retardant ABS alloy materials and made up for the performance defects of flame retardant ABS materials, which is an outstanding representative of the high performance of flame retardant ABS in recent years.

\section{Acknowledgements}

The authors would like to thanks all the technical teams from National Engineering Laboratory for Plastic Modification and Processing for their help and support to complete the experiments of this work.

\section{References}

[1] Lei W, Bin S, Enzhu H, Kunhong H, Xianguo H. Reuse of spent bleaching clay for supporting MoS2 nanoparticles as a lubricating filler in ABS plastics [J]. Tribology International. 2019, 131 (000): 415-423.

[2] Se Lyn Kim; Min Young Liyu. Adhesive strengths between glass fiber-filled ABS and metal in insert molding with engraved and embossed metal surface treatments [J]. Polymer Engineering and Science. 2019, 59 (Sup1): E93-E100.

[3] J. H. H. Rossato; H. G. Lemos; G. L. Mantovani. The influence of viscosity and composition of ABS on the ABS/SBS blend morphology and properties [J]. Journal of Applied Polymer Science. 2019, 136 (8): 4707-47075.

[4] Braga N F, LaChance A M, Liu B, et al. Influence of compatibilizer and carbon nanotubes on mechanical, electrical, and barrier properties of PTT/ABS blends [J]. Advanced Industrial and Engineering Polymer Research, 2019, 2 (3): 121-125.

[5] Wen Y D, Fang L U, Mei F H, Jun Q Z, Heng T W. Yong J L. Phenomenon of LCST-type phase behavior in SAN/PMMA systems and its effect on the PLLA/ABS blend compatibilized by PMMA-type polymers: Interface stabilization or micelle formation [J]. Polymer. 2019, 163 (000): 36-47.

[6] S Singh, N Singh, M Gupta, C Prakash, R Singh. Mechanical feasibility of ABS/HIPS-based multi-material structures primed by low-cost polymer printer [J]. Rapid Prototyping Journal. 2019, 25 (1): 152-161.

[7] A Olad, L Ranjbarian. Influence of natural clinoptilolite nanoparticles on thermal stability, scratch resistance and adherence properties of Acrylonitrile butadiene styrene (ABS) [J]. Fibers and Polymers. 2013, 14 (3): 447-452. 
[8] S. M. Hosseini, S. S. Madaeni, A. R. Khodabakhshi. Preparation and characterization of ABS/HIPS heterogeneous anion exchange membrane filled with activated carbon [J]. Journal of Applied Polymer Science. 2010, 118 (6): 3371-3383.

[9] Oluwakayode B, Gbadebo O, Mulugeta A H., Jaret C R. The influence of load direction, microstructure, raster orientation on the quasi-static response of fused deposition modeling ABS [J]. Rapid Prototyping Journal. 2019, 25 (3): 462-472.

[10] Li, H. M., Fouracre, R. A., Crichton, B. H., Banks, V. A. The influence of ions on the thermally stimulated discharge current spectra of water-treed additive-free low-density polyethylene [J]. Dielectrics and Electrical Insulation, IEEE Transactions on. 1994, 1 (6): 1084-1093.

[11] Stringari G B., Zupančič B, Kubyshkina G, et al. Time-dependent properties of bimodal POM-Application in powder injection molding [J]. Powder Technology, 2011, 208 (3): 590-595.

[12] Uthaman N, Majeed A. Impact modification of polyoxymethyl-ene (POM) [J]. e-Polymers, 2006, 6 (1) 34-42.

[13] Arslan C, Dogan M. Effect of fiber amount on mechanical and thermal properties of (3-aminopropyl) triethoxysilane treated basalt fiber reinforced ABS composites [J]. Materials Research Express, 2019, 6 (11): 115-122.

[14] Chang B P., Mohanty A K., Misra M. Sustainable biocarbon as an alternative of traditional fillers for poly (butylene terephthalate)-based composites: Thermo-oxidative aging and durability [J]. Journal of Applied Polymer Science, 2019, 136 (27): $477-482$.
[15] Frank, Z. Michael B. Fracture of a saddle fusion (weld) joint in high density polyethylene (HDPE) pipe [J]. Engineering Failure Analysis. 2017, 82 (000): 481-492.

[16] Olad A, Ranjbarian L. Influence of natural clinoptilolite nanoparticles on thermal stability, scratch resistance and adherence properties of Acrylonitrile butadiene styrene (ABS) [J]. Fibers and Polymers, 2013, 14 (3): 447-452.

[17] $\mathrm{Fu} \mathrm{Z,} \mathrm{Mao} \mathrm{Y,} \mathrm{Li} \mathrm{S,} \mathrm{et} \mathrm{al.} \mathrm{Preparation} \mathrm{and} \mathrm{characterization} \mathrm{of}$ ABS and copper (II) sulfate coordination composites by planetary ball mill [J]. Polymer Bulletin, 2018, 75 (2): 453-468.

[18] Hosseini S M., Madaeni S S., Khodabakhshi A R. Preparation and characterization of ABS/HIPS heterogeneous anion exchange membrane filled with activated carbon [J]. Journal of Applied Polymer Science, 2010, 118 (6): 3371-3383.

[19] Li H L., Zhang L X., Ding X L. Effect of PP-g-MAH on Properties of ABS/PP Blends [C]. Applied Mechanics and Materials. Trans Tech Publications Ltd, 2015, 727: 313-317.

[20] Zhang J. Research on thermostability of flame-retardant PC/ABS-Blends with PyGC [J]. Procedia Eng, 2016, 135: 83-89.

[21] Kim S L., Lyu M Y. Adhesive strengths between glass fiber-filled ABS and metal in insert molding with engraved and embossed metal surface treatments [J]. Polymer Engineering \& Science, 2019, 59 (S1): E93-E100.

[22] Kumar R M., Rajini N, Mayandi K, et al. Friction and wear properties of PTFE blended ABS polymer composite [C]. AIP Conference Proceedings. AIP Publishing LLC, 2019, 2057 (1): 75-83. 